\title{
絭 \\ Application of diamond size frequency distribution and XRT technology at a large diamond producer
}

\author{
by F. Sasman, B. Deetlefs, and P. van der Westhuyzen
}

\section{Synopsis}

Diamond size frequency distribution (SFD) curves, combined with the associated dollar per carat per size class, play an important role in the diamond industry. Value per size class is unique for each deposit and typically varies from less than a dollar per carat to several thousands of dollars per carat for special stones. Recovery of large stone therefore contributes significantly to the bottom line of a large diamond producer. While the design of the process plant should prevent damage and possible breakage of large stones, it should also ensure adequate liberation of the finer diamonds.

Innovative solutions are required to protect and recover type I and II diamonds if prominent within the resource. X-ray transmission (XRT) sorting presents the opportunity to develop flow sheet designs that incorporate a balance between exploitation of the resource and process efficiency, as well as practical capital and operating costs.

This paper serves to illustrate the role and application of SFD curves in determining optimum cut-off and re-crush sizes within the flow sheet of a large diamond producer. A thorough understanding of the unique technical and economic aspects of a deposit provides the basis from where new and innovative technologies can be proposed, allowing mining companies to maintain and improve profit margins. It highlights the results of various plant trials and newly commissioned XRT sorters for larger size fractions. It also provides recommendations for future applications of XRT machines in the diamond process flow sheet. Keywords

Diamond size frequency distribution, XRT, large diamond producer.

\section{Introduction}

Diamond particle size is described in terms of a size frequency distribution (SFD), expressed in terms of the number of stones or carats per size class. SFD curves, in combination with the value profile, are used in resource estimation, cut-off size and re-crush size selections, as well as plant performance tracking and control. The focus here is on the use of SFD curves to optimize cut-off and re-crush size selections. An understanding of the financial drivers of an operation, combined with technical knowledge and experience, provide a sound basis for optimum flow sheet development and fit-forpurpose technology selection.

Technology advances bring forward new options and combinations for diamond processing and are necessary in today's harsh economic environment. The diamond recovery step in particular has undergone vast changes over the last few years as technology from related process industries enters the minerals processing industry; specifically, the inclusion of X-ray transmission (XRT) machines into the flow sheet.

XRT machines operate on the principle of the feed material's ability to absorb X-ray radiation. As diamonds consist of carbon, which is a light element possessing an atomic number of six, they absorb less X-ray radiation than heavier elements such as silicon, calcium, and magnesium. Varying Xray energies allow the machines to discriminate between various materials based on a combination of density, thickness, and elemental composition.

Large and exceptional stones should be recovered as early as possible in the flow sheet to minimize revenue in circulation and prevent possible diamond damage (van der Westhuyzen, Bouwer, and Jakins, 2014). XRT technology is starting to prove itself in this application by limiting damage to large stones as well as allowing the recovery of type II diamonds. Type II diamonds are more susceptible to damage due to their brittle nature and since they contain very little or no nitrogen, type II diamonds do not luminesce.

Test work was carried out at a diamond mine in Southern Africa to evaluate the use of XRT machines in the recovery circuit, and the results are presented herein. The application of XRT technology in the preconcentration and concentration stages is also documented.

\section{SFD application}

The objective of any diamond operation is to obtain maximum liberation; however, given the unique size-revenue profile of diamonds, minimizing diamond damage is equally important in optimizing revenue (Rider and Roodt, 2003). Although much work has been done in mineral processing to quantify the

* Lycopodium ADP, Cape Town, South Africa.

(C) The Southern African Institute of Mining and Metallurgy, 2018. ISSN 2225-6253. Paper received Feb. 2016; revised paper received Feb. 2017. 


\section{Application of diamond size frequency distribution and XRT technology}

degree of liberation at different stages of the flow sheet, determining the inputs required for the established formulae is challenging due to the unique attributes of diamonds (Machowski, 2007). However, since the objective is ultimately to know whether a certain size diamond in a certain size host particle is going to be locked or liberated, the size ratio of diamond particle to host rock particle in combination with the preferential liberation factor (PLF) can be used as a proxy. The PLF can be defined as the size ratio of a diamond particle to host rock particle above which the diamond particle will definitely be liberated from the host rock. The mathematical expression and interpretation of the size ratio in relation with the PLF is as follows:

$$
\begin{aligned}
& \frac{d_{\text {diamond }}}{D_{\text {host rock }}}<P L F \\
& \frac{d_{\text {diamond }}}{D_{\text {host rock }}}>P L F
\end{aligned}
$$

If the ratio in Equation [1] is true, the diamond will remain locked in the host rock. If not (Equation [2]), the diamond will be liberated from the host rock.

The SFD graph indicates the number of stones or carats per size class. Given the non-uniform class widths and wide range associated with a typical distribution, practice is to convert to unit intervals using the lower critical stone size. Normalizing the size distribution is important as it ensures that the data is presented in a manner that is statistically correct. A typical SFD curve of a recovered diamond parcel (+2 $\mathrm{mm}$ diamonds) from a large diamond producer is shown in Figure 1.

Using the SFD as per Figure 1, a diamond deportment exercise was performed to determine the liberation effectiveness of $+2 \mathrm{~mm}$ diamonds. The diamond deportment exercise prepares a rectangular array, consisting of diamond size on the one axis and host rock particle size on the other axis. Each element in the array indicates a locked or liberated state. The diamond deportment is performed in parallel with the flow sheet mass balance in the process simulation package LIMN, allowing one to track the diamonds across the different streams and unit processes. Once the diamond distributions of the product streams are known, the dollar value per carat per size class is used to calculate revenue and revenue recovery.

The flow sheet in Figure 2 and data as per Table I summarize the results from the diamond deportment exercise.

The results from the diamond deportment exercise as reflected in Table I are typical for a large diamond producer,

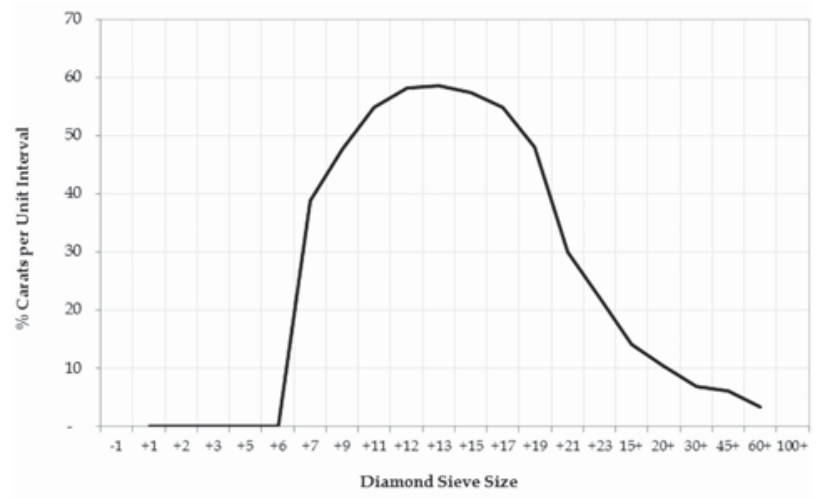

Figure 1-Diamond size frequency distribution indicating percentage carats per unit interval

\section{Table I}

Base case diamond and revenue recoveries

\begin{tabular}{|l|c|c|c|}
\hline & Description & Value & Units \\
\hline Feed & Liberated diamonds & 5 & $\mathrm{cts} / \mathrm{h}$ \\
& Locked diamonds & 7 & $\mathrm{cts} / \mathrm{h}$ \\
& Total diamonds & 12 & $\mathrm{cts} / \mathrm{h}$ \\
& Total revenue & 32064 & $\$ / \mathrm{h}$ \\
\hline Product & Diamonds & 8 & $\mathrm{cts} / \mathrm{h}$ \\
& Revenue & 30981 & $\$ / \mathrm{h}$ \\
\hline Recovery & Diamonds & 66 & $\%$ \\
& Revenue & 97 & $\%$ \\
& & & $\%$
\end{tabular}

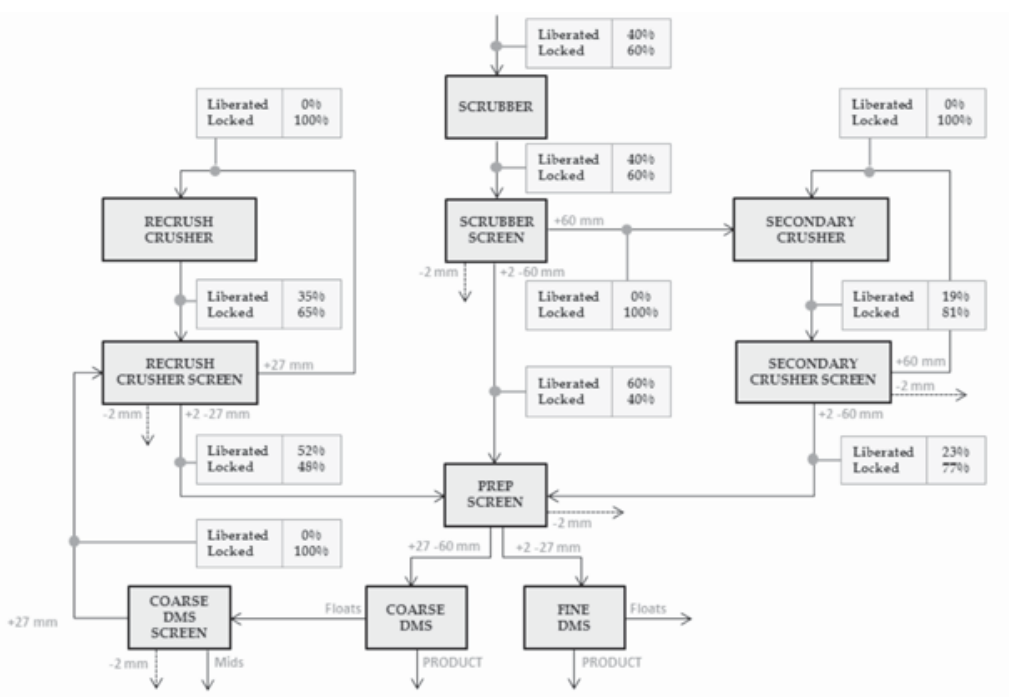

Figure 2-Base case flow sheet indicating per cent liberated and per cent locked carats throughout the flow sheet 


\section{Application of diamond size frequency distribution and XRT technology}

with $97 \%$ revenue recovery even though more than $30 \%$ of the diamonds are not recovered. However, it is important to keep in mind that in situ diamond content is not accurately reflected by the recovered diamond parcel. Size distributions based on sales parcels or production samples are not a total content curve and as such not a true reflection of the diamond and revenue recovery potential of a deposit. The illustrated diamond deportment calculation also assumed $100 \%$ recovery of liberated diamonds and zero recovery of locked diamonds in the process plant and recovery circuit. The assumptions on which the diamond deportment exercise and subsequent revenue analysis are based are important and dictate whether the results should be interpreted on an absolute or comparative basis.

\section{Impact of cut-off size on diamond and revenue recoveries}

\section{Bottom cut-off size (BCOS)}

$\mathrm{BCOS}$ refers to the smallest diamond the plant is designed to recover and in this exercise is equal to a bottom screen size aperture of $2 \mathrm{~mm}$. Increasing the BCOS to $5 \mathrm{~mm}$ will result in a lower diamond and revenue recovery, but on the upside, the operational cost required to recover the diamonds decreases.

Table II indicates that even though the diamond recovery decreases significantly from $66 \%$ to $39 \%$ when increasing the BCOS from $2 \mathrm{~mm}$ to $5 \mathrm{~mm}$, the decrease in revenue recovery is less than $2 \%$.

The distribution in Figure 3 illustrates that most of the revenue is associated with the larger diamonds and therefore the revenue recovery is still acceptable at a relative coarse $\mathrm{BCOS}$ of $5 \mathrm{~mm}$. The BCOS is typically determined by the mineral resource management department and is dependent on market conditions.

\section{Middle cut-off size (MCOS)}

The MCOS dictates the size fraction that reports to the recrush stage and is driven by the requirement to attain maximum liberation without causing diamond damage. The base case evaluation was performed at a MCOS of $27 \mathrm{~mm}$.

The decrease in MCOS brings about a small increase in liberation and subsequent diamond and revenue recoveries. However, decisions pertaining to MCOS selection are complex, encompassing a number of aspects such as the risk of diamond damage, capital and operating cost implications, recycle loads, and plant stability. The result as per Table III is just one of the aspects to be included in the trade-off decision.

\begin{tabular}{|c|c|c|}
\hline \multicolumn{3}{|l|}{ Table II } \\
\hline \multicolumn{3}{|c|}{$\begin{array}{l}\text { Diamond and revenue recoveries at a BCOS of } \\
2 \mathrm{~mm} \text { and } 5 \mathrm{~mm}\end{array}$} \\
\hline Description & $\mathrm{BCOS}$ at $2 \mathrm{~mm}$ & $\mathrm{BCOS}$ at $5 \mathrm{~mm}$ \\
\hline $\begin{array}{l}\text { Diamond recovery } \\
\text { Revenue recovery }\end{array}$ & $\begin{array}{l}66 \% \\
97 \%\end{array}$ & $\begin{array}{l}39 \% \\
95 \%\end{array}$ \\
\hline
\end{tabular}

\section{XRT applications}

XRT machines can be applied at three areas within a diamond process flow sheet. Figure 4 illustrates the inclusion of XRT machines in the preconcentration, concentration, and recovery steps. Although large diamonds are extremely rare and valuable, many operations do not specifically cater for upstream equipment to recover them. Recently, however, there has been a renewed interest from diamond mining operators in recovering larger diamonds as a single large diamond represents significant value compared to the same stone broken into smaller pieces (Webb, 2014).

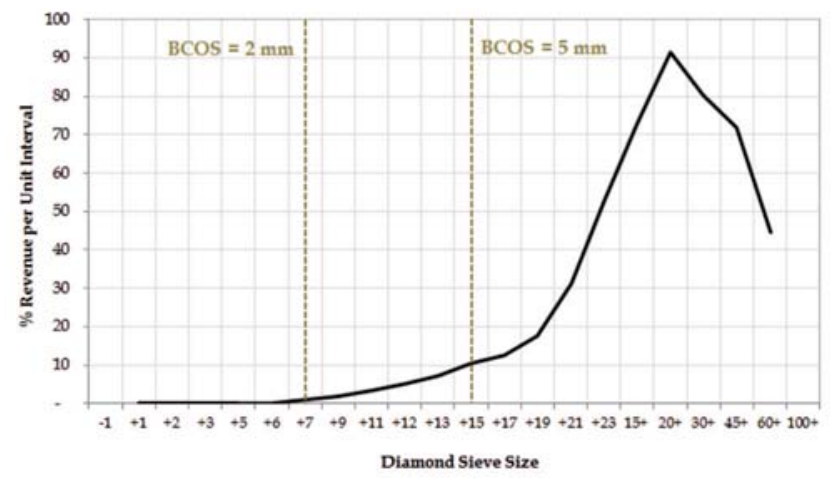

Figure 3-Revenue distribution per unit interval

Table III

Diamond and revenue recoveries at a MCOS of $27 \mathrm{~mm}$ and $24 \mathrm{~mm}$

\begin{tabular}{|l|c|c|}
\hline Description & MCOS at 27 $\mathbf{~ m m}$ & MCOS at 24 $\mathbf{~ m m}$ \\
\hline Diamond recovery & $66 \%$ & $67 \%$ \\
Revenue recovery & $97 \%$ & $97 \%$ \\
\hline
\end{tabular}

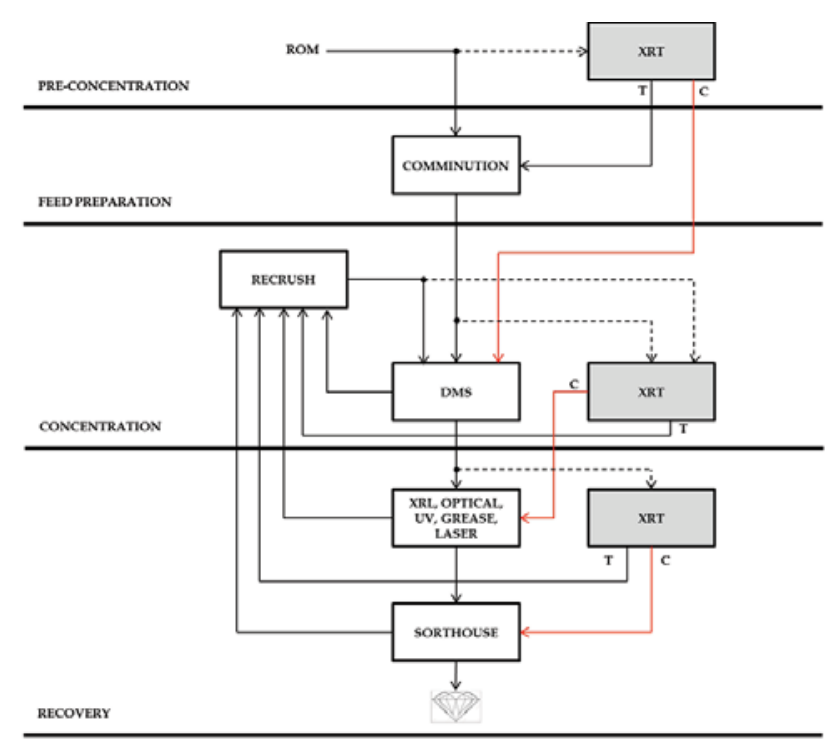

Figure 4-XRT placement in a typical diamond flow sheet 


\section{Application of diamond size frequency distribution and XRT technology}

\section{$X R T$ in preconcentration}

\section{Waste sorter application}

Open pit diamond mines are associated with high stripping ratios. As a result, the preconcentration of run-of-mine (ROM) ore using XRT technology can potentially offer huge economic benefits, including lower operating costs, energy savings, increased throughput, and improved steady-state operations due to less recirculation of the harder constituents. Typically, the ROM is scalped and the undersize fraction is fed to the XRT machines. This step greatly reduces the amount of waste material entering the main treatment plant by applying the discrimination principle on the diamond-bearing ores upfront.

\section{Bulk sorter application}

XRT machines can also be used as bulk sorters to recover large diamonds in the preconcentration step. Extraction of large diamonds as early as possible in the flow sheet has the advantage of increasing the recovery of larger diamonds as well as an overall reduction in diamond damage by avoiding exposing the diamonds to subsequent crushing operations.

\section{$X R T$ in concentration}

The conventional diamond processing flow sheet employs dense medium separation (DMS) in the concentration step. The advantages and disadvantages of using XRT machines in the concentration step are listed in Table IV.

\section{$X R T$ in recovery}

Several methods exist to treat diamond ores in the recovery step. These include separation technologies based on the principles of X-ray luminescence (XRL), X-ray transmission, hydrophobicity (grease tables/belts/drums), infrared (heat conduction), optical (scattering of light and specula reflection of light by diamonds), and laser and ultraviolet discrimination. XRL separation is one of the most basic and common methods of treating diamond ores, and has been applied successfully in diamond plants for more than 40 years (Tirmyaev et al., 2007). XRL operates on the principle of a diamond's property of luminescing under irradiation by an incident X-ray beam.

The advantages and disadvantages of XRL technology in the recovery step are listed in Table V.

A typical large diamond recovery process applies XRT machines post-DMS. The DMS concentrate is fed to recovery; where it is initially sized to XRT feed stream specifications. Generally, this follows a 3:1 feed size distribution. This implies that the top cut-off size (TCOS) is three times the $\mathrm{BCOS}(e . g .,+5 \mathrm{~mm}-15 \mathrm{~mm})$. The advantages and disadvantages of using XRT in the recovery step are listed in Table VI.

A typical XRT recovery flow sheet is presented in Figure 5. Concentrate is sized into middles $+5 \mathrm{~mm}$ to $15 \mathrm{~mm}$ and coarse $+15 \mathrm{~mm}$ to $60 \mathrm{~mm}$ fractions and fed to two separate XRT machines. The XRT concentrate streams are dried and report to a sort house. The XRT tails fraction is sent to recrush for recycling. The tails could also be reprocessed through the recovery stage to increase process efficiency.

\section{XRT test work}

The primary aim of the XRT test work was to evaluate the unit's ability to recover all diamonds (type I and II) and tracers all the time. The secondary aim was to increase mine revenue by using appropriate technology to improve recovery, reduce diamond damage, increase operational efficiencies, and enhance security of the product.

Advantages and disadvantages of XRT in the concentration step

\begin{tabular}{|l|c|}
\hline Advantages & Disadvantages \\
\hline - Lower capital expenditure (CAPEX) than DMS for diamond recovery from larger size fractions & - Higher CAPEX than alternative bulk sorting techniques \\
\hline - Efficient recovery of all diamond types (I and II) & - Restriction on BCOS \\
\hline - Potentially low-yielding process & \\
\hline - Maximizes the recovery of large, high-value stones and minimizes breakage & \\
\hline - Does not require the material to be exposed to be detected & \\
\hline - Environmentally friendly technology & \\
\hline
\end{tabular}

\section{Table $\mathrm{V}$}

Advantages and disadvantages of $X R L$ in the recovery step

\begin{tabular}{|l|l|}
\hline Advantages & \multicolumn{1}{c}{ Disadvantages } \\
\hline - Proven technology within the diamond industry & $\begin{array}{l}\text { - Traditionally lower throughputs: a monolayer of feed material is } \\
\text { required to be presented to the X-ray source }\end{array}$ \\
\hline - Recovers high-luminescing diamonds efficiently & $\begin{array}{l}\text { - Susceptible to contaminants: for example calcites and sea shells } \\
\text { in alluvial diamond applications }\end{array}$ \\
\hline - Lower capital expenditure when compared to XRT and DMS & $\begin{array}{l}\text { - Inability to detect type II diamonds and other low-luminescing diamonds } \\
\text { - Dependant on material temperature - diamond luminescence is a function of temperature }\end{array}$ \\
\hline
\end{tabular}




\section{Application of diamond size frequency distribution and XRT technology}

\begin{tabular}{|c|c|}
\hline \multicolumn{2}{|l|}{ Advantages and disadvantages of XRT in the recovery step } \\
\hline Advantages & Disadvantages \\
\hline $\begin{array}{l}\text { - Redefined flow sheet: simplifies the diamond recovery process while significantly } \\
\text { reducing operating costs }\end{array}$ & - High initial costs (CAPEX) \\
\hline - Automation: minimal or no manual handling required during preconcentration and recovery & - Restriction on BCOS \\
\hline $\begin{array}{l}\text { - Increased recovery rates: technology produces highly efficient sorting by recovering liberated and } \\
\text { unliberated diamonds as well as luminescent and non-luminescent diamonds (type I and II) }\end{array}$ & $\begin{array}{l}\text { - Susceptible to carbon-based contaminants: these } \\
\text { include plastics and screen panel pins }\end{array}$ \\
\hline \multicolumn{2}{|l|}{ - Water requirements: little or no water required } \\
\hline \multicolumn{2}{|l|}{ - Higher throughputs: dependent on feed size range } \\
\hline - Diamond surface properties: less influenced by dust and slime on the surface of the diamond & \\
\hline - Large diamond recovery: large diamonds can be recovered before secondary and tertiary crushing & \\
\hline
\end{tabular}

Table VII

Large diamond recovery XRT application test work: summary of results

\begin{tabular}{|l|c|c|}
\hline Test description & Middles fraction $\mathbf{+ 5} \mathbf{~ m m} \mathbf{- 1 5} \mathbf{~ m m}$ & Coarse fraction $+\mathbf{1 5} \mathbf{m m}-\mathbf{6 0} \mathbf{~ m m ~}$ \\
\hline 1. Tracers only & $100 \%$ & $100 \%$ \\
2. Tracers with gravel & $100 \%$ & $100 \%$ \\
3. Diamonds only & $100 \%$ & $100 \%$ \\
4. Diamonds with gravel & $100 \%$ & $100 \%$ \\
\hline
\end{tabular}

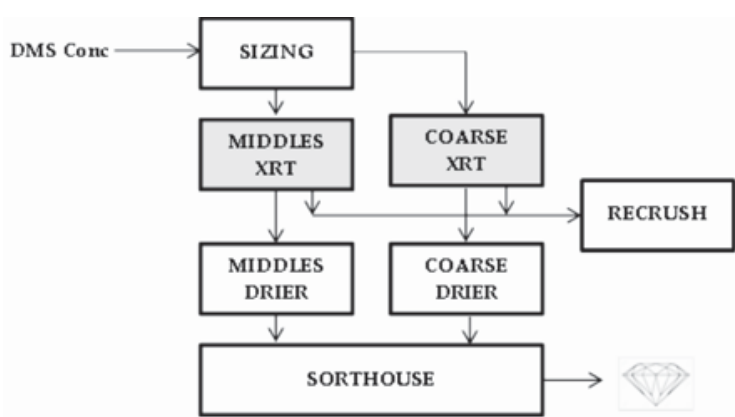

Figure 5-Typical XRT recovery flow sheet

\section{Test work outline}

Four different tests were carried out, and each test was repeated three times to aid in assessing the performance repeatability of the XRT machine. Test 1 was carried out using tracers only, test 2 utilized tracers with gravel, test 3 utilized diamonds only, and test 4 used diamonds with gravel. Table VII summarizes the test work outline and results.

The diamonds used during the test work consisted of different coloured gem-quality stones, boart diamonds, and type I and II diamonds (see Figure 6). For tests carried out with gravel, the sample feed constituted of $100 \mathrm{~kg}$ of prescreened $(-15 \mathrm{~mm})$ material. During each test the XRT machines recovered all of the tracers and diamonds from both the middles and the coarse fraction.

\section{$X R T$ yields and grams per ejection}

A single test, based on operating the entire recovery plant, was carried out to evaluate the yield of the middles and coarse XRT machines. The middles machine yielded 0.03\%

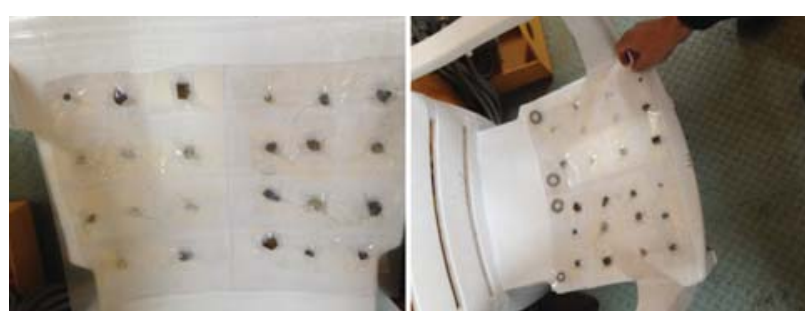

Figure 6-Gem-quality, boart, and type I and type II diamonds used in XRT test work

and the coarse machine $0.27 \%$.

Grams per ejection can be defined as the associated mass of material ejected once the XRT machine has detected carbon-based matter and triggers the jet of air used to move the detected material from its normal process path to the concentrate chute. Only the middles XRT machine was tested for associated grams per ejection, and it was found that the minimum associated mass per ejection was $0.7 \mathrm{~g}$, with a maximum of $1.7 \mathrm{~g}$. This attribute is a function of feed size distribution and can therefore increase, depending on the TCOS.

\section{Conclusion}

Basic diamond process plant design principles utilized in conjunction with SFD and revenue distribution data have proved to be a powerful analytical tool for process design engineers. This method allows the engineer to make improved decisions when faced with the risks and complexities associated with the incorporation of new technology into proven flow sheets. As with the addition of any new technology, risks related to process efficiency, and capital/operating costs should be traded off and the ultimate 


\section{Application of diamond size frequency distribution and XRT technology}

decision should be made on applicability and appropriateness.

The XRT algorithm selected during the large diamond recovery test work resulted in $100 \%$ of the diamonds being discriminated and ejected to the concentrate stream. For future XRT applications in flow sheets for recovering large diamonds, it is recommended that attention is given to the feed preparation step. Upstream product degradation resulting in additional fines generation could cause the XRT machine to produce much higher yields than initially expected, which could significantly and unnecessarily affect the sizing of downstream equipment.

From the large diamond recovery test work presented, it can be concluded that there is a noticeable role for XRT machines within a traditional diamond process flow sheet. It goes without saying that the addition of XRT machines should follow the systematic approach of process design, including ore dressing studies, development of design criteria, trade-off studies, and the ultimate establishment of applicable and appropriate flow sheets.

\section{References}

Anon. 2013. Diamonds sensor-based ore sorting since 1988. www.tomra.com [Accessed 12 October 2015].
file:///C:/Users/User/AppData/Local/Temp/TSMI_11_Segment\%20Guide\%20\%20Diamonds_english_WEB-2.pdf

Bush, D. 2010. An overview of the estimation of kimberlite diamond deposits. Proceedings of Diamonds - Source to Use 2017, Gaborone, Botswana, 1-3 March 2010. Southern African Institute of Mining and Metallurgy, Johannesburg. pp. 73-84.

FERREIRA, J. 2013. Sampling and estimation of diamond content in kimberlite based on microdiamonds. Doctoral thesis, Ecole Nationale Supérieure des Mines de Paris.

MacношsкI, R. 2007. Technique for estimation of diamond lockup in a diamond processing plant. Proceedings of Dianinds - Source to Use 2007. Southern African Institute of Mining and Metallurgy, Johannesburg.

Rider, P.J. AND Roodt, A. 2003. Diamond value management - knowledge management and the measurement of value addition. Journal of the South African Institute of Mining and Metallurgy, vol. 103, no. 9. pp.551-556.

Riedel, F. and DehleR, M. 2010. Recovery of unliberated diamonds by X-ray transmission sorting. Proceedings of Diamonds - Source to Use 2017, Gaborone, Botswana, 1-3 March 2010. Southern African Institute of Mining and Metallurgy, Johannesburg. pp. 193-199.

Tirmyaev, A., Kulikov, R., Potashnikov, A., and Sysoev, E. 2007. New methods and instruments in mining. Journal of Mining Science, vol. 43, no. 5. pp. 555-564.

VAn DER Westhuyzen, P., Bouwer, W., and Jakins, A. 2014. Current trends in the development of new or optimization of existing diamond processing plants, with focus on beneficiation. Journal of the Southern African Institute of Mining and Metallurgy, vol. 114. pp. 537-546.

Webb, M. 2014. DebTech develops new diamond sorters to fill gap. http://www.miningweekly.com/article/debtech-develops-new-diamondsorters-to-fill-gap-2014-07-24 [Accessed 12 October 2015].

\section{Why choose Geobrugg?}

- For the most valuable asset in life - our safety

- High tensile steel mesh

- Blast resistant

- Different mesh types for different ground conditions

- Proven static and dynamic performance

- Cutting edge corrosion protection

- Tailor-made sheet sizes

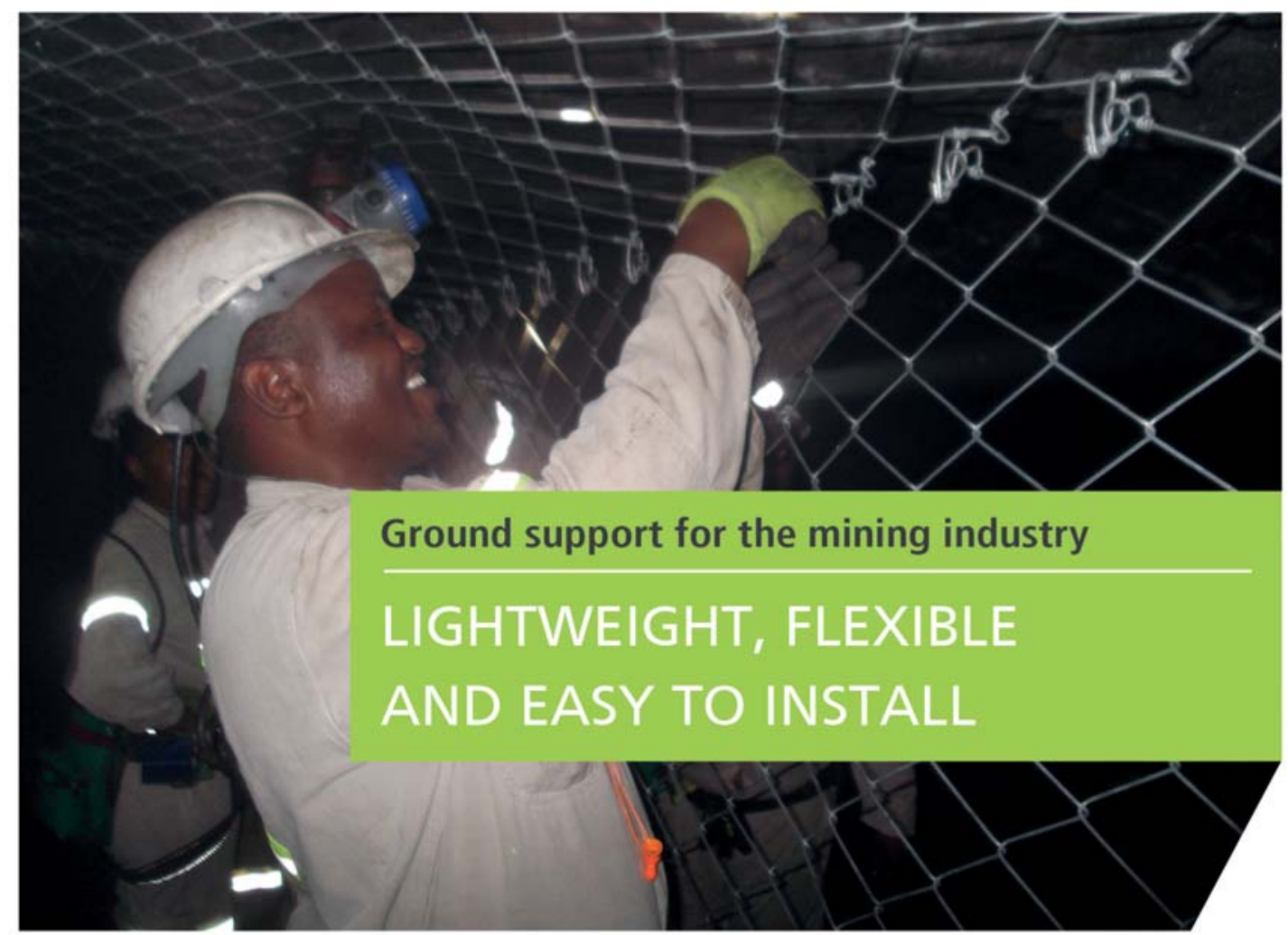

Geobrugg Southern Africa (Pty) Ltd | Unit 3 Block B Honeydew Business Park | 1503 Citrus Street | Honeydew 2170 | South Africa | T +27 117943248 | info@geobrugg.com | www.geobrugg.com 